bis 100000 dieser Einheiten der Vererbung - stellen sie die Reihenfolge der Abschnitte auf der Desoxyribonukleinsäure, der DNA, fest (Sequenzen der Nukleotide, von denen jede Körperzelle zweimal drei Milliarden besitzt). In einem zweiten Schritt wird festgestellt, welches Merkmal an welcher Stelle sitzt, die Kartierung der Gene.

In den USA ist das Nationale Gesundheitsinstitut an dieser Arbeit, die Japaner preisen dafür ihr Human Frontier Program international an, seit einem Jahr gibt es HUGO, die internationale wissenschaftliche Human-Genom-Organisation, die Europäische Gemeinschaft wollte mit einem Programm der „prädiktiven Medizin“ einsteigen. In der Bundesrepublik gibt es einstweilen nur verstreute Ansätze. Die Totalsequenzierung gilt hier noch nicht als vordringliches Forschungsziel. Böckle kommt es vor allem darauf an, in der Gesellschaft von unten her Verständnis für die Genforschung aufzubauen. Deshalb schätzt er auch die Mitgliedschaft von zwei Gewerkschaftern im Arbeitskreis besonders hoch ein. Er distanzierte sich von dem von der EG-Kommission geprägten Begriff „prädiktive Medizin“ - der inzwischen ad acta gelegt wurde - , weil er zur Eugenik hinneige. Bisher sind die Naturwissenschaftler ziemlich hilflos - sie können nur wie etwa der Präsident der Deutschen Forschungsgemeinschaft, Prof. Dr. Hubert Markl, feststellen, es sei eine Herausforderung für die ärztliche Ethik, mögliche oder sichere spätere Krankheitsentwicklungen voraussagen zu können. Eine Antwort darauf steht aber noch aus. Das heißt aber vor allem, daß man die Anwendung der Genomanalyse nicht technokratisch anpacken darf. Das Risiko ist dafür zu groß.

\section{Information über Umweltforschung}

Mehr als eine Milliarde DM sind in den letzten drei Jahren für Umweltforschung im Bereich der Luft ausgegeben worden, jeweils rund eine halbe Milliarde DM entfielen auf Energie und Rohstoffe, Wasser und Strahlung. Der Umweltforschungskatalog 1988 (UFOKAT '88) des Umweltbundesamtes (Erich Schmidt Verlag, Berlin) stellt rund 3900 Forschungsprojekte vor, die nach dem 1. April 1986 beendet wurden oder noch laufen. Insgesamt wurden dafür 3,5 Milliarden DM aufgewendet. Die Datenbank für Umweltforschung im Rahmen des Informations- und Dokumentationssystems Umwelt (UMPLIS) des Berliner Amtes, aus der UFOKAT ein Auszug ist, enthält rund 25000 Forschungsvorhaben. Sie kann ebenso wie die Umweltliteraturdatenbank online bei den Hosts DATA-STAR, Radio Schweiz $A G$, Bern, und STN International, Karlsruhe, genutzt werden.

\title{
Erratum
}

T. Dittrich, R. Graham: Quantenchaos: Komplexe Dynamik im Grenzbereich zwischen mikroskopischer und makroskopischer Physik

Naturwissenschaften 76, $401-409$ (1989)

Fig. $6 a$ und $b$ auf S. 408 sind vertauscht.

Verantwortlich für den Anzeigenteil: E. Lückermann, Heidelberger Platz 3, D-1000 Berlin 33. - ๑ Springer-Verlag, Berlin-Heidelberg 1989. Springer-Verlag GmbH \& Co. KG, D-1000 Berlin 33. - Satz; Mitterweger Werksatz GmbH, D-6831 Plankstadt. Druck: Druckhaus Beltz, D-6944 Hemsbach - Printed in Germany, 